\title{
Inhibitors of glutamate dehydrogenase block sodium-dependent glutamate uptake in rat brain membranes
}

\author{
Brendan S. Whitelaw ${ }^{1}$ and Michael B. Robinson ${ }^{1,2 *}$ \\ Children's Hospital of Philadelphia Research Institute, Philadelphia, PA, USA \\ ${ }^{2}$ Departments of Pediatrics and Pharmacology, University of Pennsylvania, Philadelphia, PA, USA
}

Edited by:

Leif Hertz, China Medical University, China

\section{Reviewed by:}

Mary McKenna, University of

Maryland, USA

Lasse Kristoffer Bak, University of

Copenhagen, Denmark

\section{*Correspondence:}

Michael B. Robinson, Department of Pediatrics, University of Pennsylvania, 502N Abramson Pediatric Research Building, 3615 Civic Center Boulevard, Philadelphia, PA 19104-4318, USA e-mail: robinson@mail.

med.upenn.edu
We recently found evidence for anatomic and physical linkages between the astroglial $\mathrm{Na}^{+}$-dependent glutamate transporters (GLT-1/EAAT2 and GLAST/EAAT1) and mitochondria. In these same studies, we found that the glutamate dehydrogenase (GDH) inhibitor, epigallocatechin-monogallate (EGCG), inhibits both glutamate oxidation and $\mathrm{Na}^{+}-$ dependent glutamate uptake in astrocytes. In the present study, we extend this finding by exploring the effects of EGCG on $\mathrm{Na}^{+}$-dependent L-[$\left.{ }^{3} \mathrm{H}\right]$-glutamate (Glu) uptake in crude membranes (P2) prepared from rat brain cortex. In this preparation, uptake is almost exclusively mediated by GLT-1. EGCG inhibited L-[3 H]-Glu uptake in cortical membranes with an $\mathrm{IC}_{50}$ value of $230 \mu \mathrm{M}$. We also studied the effects of two additional inhibitors of $\mathrm{GDH}$, hexachlorophene (HCP) and bithionol (BTH). Both of these compounds also caused concentration-dependent inhibition of glutamate uptake in cortical membranes. Pre-incubating with HCP for up to 15 min had no greater effect than that observed with no pre-incubation, showing that the effects occur rapidly. HCP decreased the $V_{\text {max }}$ for glutamate uptake without changing the $K_{\mathrm{m}}$, consistent with a non-competitive mechanism of action. EGCG, HCP, and BTH also inhibited $\mathrm{Na}^{+}$-dependent transport of $\left.\mathrm{D}-{ }^{3} \mathrm{H}\right]$-aspartate (Asp), a non-metabolizable transporter substrate, and [ $\left.{ }^{3} \mathrm{H}\right]-\gamma$-aminobutyric acid (GABA). In contrast to the forebrain, glutamate uptake in crude cerebellar membranes (P2) is likely mediated by GLAST (EAAT1). Therefore, the effects of these compounds were examined in cerebellar membranes. In this region, none of these compounds had any effect on uptake of either L-[ $\left.{ }^{3} \mathrm{H}\right]$-Glu or D- $\left[{ }^{3} \mathrm{H}\right]-\mathrm{Asp}$, but they all inhibited $\left[{ }^{3} \mathrm{H}\right]-\mathrm{GABA}$ uptake. Together these studies suggest that $\mathrm{GDH}$ is preferentially required for glutamate uptake in forebrain as compared to cerebellum, and GDH may be required for GABA uptake as well. They also provide further evidence for a functional linkage between glutamate transport and mitochondria.

Keywords: glutamate, GLT-1, EAAT2, GLAST, GABA, glutamate dehydrogenase, sodium-dependent uptake, epigallocatechin-monogallate

\section{INTRODUCTION}

Glutamate is the predominant excitatory neurotransmitter in the mammalian CNS and mediates the vast majority of cell-to-cell communication in the brain [for review, see (1)]. In addition to being required for millisecond cell-to-cell communication, plasticity of excitatory synaptic transmission likely underlies learning and memory [for reviews, see (1-3)]. Aberrant glutamatergic transmission has been implicated in a wide variety of neurodevelopmental, neurologic, and psychiatric conditions [for review, see (3)]. For example, an accumulation of glutamate in the extracellular space and the consequent excessive activation of glutamate receptors likely contributes to the cell death that is observed after acute insults to the nervous system, such as stroke and head trauma [for review, see (2)].

Extracellular glutamate is cleared by $\mathrm{Na}^{+}$-dependent glutamate transport systems [for reviews, see (4-6)]. In mammals, there are five $\mathrm{Na}^{+}$-dependent glutamate transporter gene products; these are called excitatory amino acid transporters (EAAT1-5). EAAT1 (also called GLAST) is found on glia; expression is enriched in cerebellum but also found throughout forebrain (7). EAAT2 (also called GLT-1) is essentially restricted to astroglia with modest expression by a subset of neurons in hippocampus $(7,8)$. Results from several different types of studies strongly suggest that GLT-1 and GLAST mediate the bulk of glutamate uptake in the mammalian brain [(9); for review, see (10)]. This clearance into astroglia differentiates glutamate from most of the other classical neurotransmitters that are directly recycled back into the presynaptic nerve terminal [for reviews, see $(11,12)]$. These transporters co-transport three $\mathrm{Na}^{+}$ions and one $\mathrm{H}^{+}$with glutamate in the inward direction; the cycle is completed with the counter-transport one $\mathrm{K}^{+}$ion (13). With this stoichiometry, these transporters are capable of generating up to a one million-fold concentration gradient of glutamate across the plasma membrane [for review, see (14)]. 
The astroglial transporters, GLT-1 and GLAST, are enriched on fine astroglial processes near synapses in vivo $(15,16)$. As might be expected, recent studies suggest that these transporters co-compartmentalize with the enzymes/organelles that would be required to efficiently fuel transport in these spatially restricted domains (17). For example, GLT-1 or GLAST co-localize with and physically/functionally interact with the $\mathrm{Na}^{+} / \mathrm{K}^{+}$ATPase (18). Recently we showed that GLT-1 is part of a co-immunoprecipitable complex with the $\mathrm{Na}^{+} / \mathrm{K}^{+}$-ATPase, most of the glycolytic enzymes, and a subset of mitochondrial proteins (17). We also demonstrated significant co-localization of GLT-1 with a mitochondrial protein in vivo and anatomic overlap of mitochondria with GLT-1 in individual astrocytes in organotypic slice cultures. In a subsequent study, we documented similar interactions and anatomic overlap between GLAST and mitochondrial proteins (19). In this later study, we measured the percentage of glutamate that is oxidized in astrocytes. We also examined the effect of an inhibitor of glutamate dehydrogenase (GDH), a mitochondrial enzyme that could contribute to glutamate oxidation, on glutamate uptake and found that it inhibited uptake in astrocytes (19). This effect was not characterized beyond testing of a single concentration of one inhibitor in astrocytes that only express GLAST. In the present study, we characterized the potential effects of inhibitors of GDH on uptake in crude rat brain membranes (P2).

\section{MATERIALS AND METHODS MATERIALS}

Adult male Sprague-Dawley rats were obtained from Charles River (Wilmington, MA, USA). All protocols were reviewed and approved by the Institutional Animal Care and Use Committee of the Children's Hospital of Philadelphia (Philadelphia, PA, USA). L- $\left[{ }^{3} \mathrm{H}\right]$ Glu $(40-80 \mathrm{Ci} / \mathrm{mmol}), \mathrm{D}-\left[{ }^{3} \mathrm{H}\right]$ Asp $(10-25 \mathrm{Ci} / \mathrm{mmol})$, and $\gamma$-amino $\left[{ }^{3} \mathrm{H}\right]$ butyric acid $\left(\left[{ }^{3} \mathrm{H}\right] \mathrm{GABA} ; 70-100 \mathrm{Ci} / \mathrm{mmol}\right)$ were obtained from PerkinElmer (Waltham, MA, USA). The specific activity of all ligands was diluted with non-radioactive L-Glu, DAsp, or GABA, respectively (Sigma-Aldrich Co., St. Louis, MO, USA). (-)-Epigallocatechin-monogallate (EGCG; $\geq 95 \%$, from green tea), hexachlorophene (HCP), bithionol (BTH), Hepes, $\mathrm{KCl}, \mathrm{CaCl}_{2}$, and $\mathrm{K}_{2} \mathrm{HPO}_{4}$ were obtained from Sigma-Aldrich Co. (St. Louis, MO, USA). Tris base, Tris $\mathrm{HCl}, \mathrm{NaCl}, \mathrm{MgCl}_{2}$, dextrose, and sucrose were obtained from Fisher Scientific (Pittsburgh, PA, USA). Tween-20 was obtained from Bio-Rad (Hercules, CA, USA).

\section{MEMBRANE PREPARATIONS}

Crude membranes (P2) were prepared from cortex and cerebellum as previously described (20). The preparation is commonly referred to as "crude synaptosomal membranes." In the current paper, we refer to this preparation as crude membranes (P2) to avoid giving the impression that it contains strictly neuronal elements. Cortex or cerebellum was dissected on a metal plate cooled to $4^{\circ} \mathrm{C}$. All subsequent steps were performed at $4^{\circ} \mathrm{C}$. The tissue was homogenized in 20 volumes (wet weight of tissue) of icecold $0.32 \mathrm{M}$ sucrose using a Dounce Teflon/glass homogenizer at $400 \mathrm{rpm}$ for seven strokes (tissue homogenate) and centrifuged at $800 \times g$ for $10 \mathrm{~min}$. The supernatant (S1) was then centrifuged at $20,000 \times g$ for $20 \mathrm{~min}$. In a subset of experiments, the resultant supernatant was collected (S2). The resultant pellet (P2) was resuspended in 40 vols. of sucrose $(0.32 \mathrm{M})$ by vortexing and centrifuged at $20,000 \times g$ for $20 \mathrm{~min}$. This washed crude membrane pellet (P2) was resuspended by vortexing in 50 vols. of sucrose $(0.32 \mathrm{M})$ and homogenized (two strokes at $400 \mathrm{rpm})$. This resulted in a suspension of approximately $30 \mu \mathrm{g}$ of protein per $50 \mu \mathrm{l}$ as determined by the Pierce BCA (bicinchoninic acid) protein assay (Thermo Scientific, Rockford, IL, USA).

\section{WESTERN BLOT ANALYSES}

The subcellular fractions were mixed with equal volumes of Laemmli sample buffer. Dual color molecular weight marker (Bio$\mathrm{Rad})$ and 3 or $10 \mu \mathrm{g}$ of protein from each fraction were resolved on $10 \%$ SDS-polyacrylamide gels, and transferred to immobilon FL polyvinylidene fluoride (PVDF) membranes (Millipore, Bedford, MA, USA) as described previously $(17,19)$. The PVDF membranes were blocked in TBS-T (50 mM Tris, $\mathrm{pH} 8.0,150 \mathrm{mM}$ $\mathrm{NaCl}, 0.1 \%$ Tween-20) containing 5\% non-fat dry milk for $1 \mathrm{~h}$ at $25^{\circ} \mathrm{C}$. The membranes were then probed with the appropriate antibody overnight at $4^{\circ} \mathrm{C}$ : rabbit anti-GLT-1 (1:5,000; Dr. Rothstein), mouse anti-GLAST (1:50; Miltenyi Biotec, Auburn, CA, USA), mouse anti- $N$-methyl-D-aspartate (NMDA) receptor subunit 1 (NR1; 1:500; BD Biosciences, San Jose, CA, USA), rat anti-glial fibrillary acidic protein (GFAP; 1:500; Dr. Lee), or goat anti-neurofilament light polypeptide (NF-L; 1:250; Santa Cruz Biotechnology, Santa Cruz, CA, USA). The membranes were then washed with TBS-T containing $1 \%$ milk and incubated with the appropriate fluorescently conjugated anti-mouse, anti-rabbit, anti-goat, or anti-rat antibodies (1:10,000; LiCor Biosciences, Lincoln, NE, USA). Blots were scanned using an Odyssey Infrared Imager (LiCor Biosciences). The yield was calculated as the percentage of total immunoreactivity found in a particular fraction divided by the total immunoreactivity found in the tissue homogenate. The enrichment was calculated as the total immunoreactivity found in a particular fraction divided by the total amount of protein found in the fraction; this was normalized to the tissue homogenate. Therefore a number greater than 1 reflects relative enrichment in a fraction compared to homogenate.

\section{TRANSPORT ASSAYS}

Sodium-dependent transport of $\mathrm{L}_{-}\left[{ }^{3} \mathrm{H}\right] \mathrm{Glu}, \mathrm{D}-\left[{ }^{3} \mathrm{H}\right] \mathrm{Asp}$, and $\left[{ }^{3} \mathrm{H}\right]$ GABA was measured as previously described (20). Duplicate assays were performed in a final volume of $0.5 \mathrm{ml}$ containing Tris base ( $5 \mathrm{mM})$, HEPES (10 mM), $\mathrm{NaCl}(140 \mathrm{mM}), \mathrm{KCl}(2.5 \mathrm{mM})$, $\mathrm{CaCl}_{2}(1.2 \mathrm{mM}), \mathrm{MgCl}_{2}(1.2 \mathrm{mM}), \mathrm{K}_{2} \mathrm{HPO}_{4}(1.2 \mathrm{mM})$, dextrose $(10 \mathrm{mM})$, and substrate in the absence or presence of inhibitors $(\mathrm{pH}=7.2)$. In parallel assays, the uptake was measured in the absence of sodium with the substitution of equimolar amounts of choline chloride for $\mathrm{NaCl}$. As HCP and BTH are not readily soluble in aqueous solutions, they were first dissolved in ethanol (HCP) or dimethyl sulfoxide (BTH) as $10 \mathrm{mM}$ stocks. These stocks were diluted such that the same concentration of solvent $(0.1 \%$ final concentration) was added to each assay; this meant that the highest concentrations of $\mathrm{HCP}$ or $\mathrm{BTH}$ used in these assays were 
$10 \mu \mathrm{M}$. In all experiments, $0.1 \%$ solvent (ethanol or dimethyl sulfoxide) was added to control assays and this concentration had no effect on uptake (data not shown, $n=3$ ). EGCG was prepared and diluted in uptake buffer immediately before measuring uptake. All components excluding the crude membranes were combined into $12 \mathrm{~mm} \times 75 \mathrm{~mm}$ glass tubes and equilibrated to $37^{\circ} \mathrm{C}$. The assay was initiated with the addition of $\mathrm{P} 2$ membranes $(50 \mu \mathrm{l})$ and stopped with $2 \mathrm{ml}$ of ice-cold $\left(4^{\circ} \mathrm{C}\right)$ choline-containing buffer after 3 min. For analyses of the effects of pre-incubation with HCP, the assay was initiated with the addition of radioactive substrate to the crude membranes (P2) incubated with HCP. After the addition of cold choline-containing buffer, the assays were filtered onto pre-wetted glass filter paper (FP-100; Brandel, Gaithersburg, MD, USA) using a cell harvester (Brandel, Gaithersburg, MD, USA). Filters were rinsed three times with $2 \mathrm{ml}$ of cold choline-containing buffer. The radioactivity trapped in the membranes was solubilized with $5 \mathrm{ml}$ of Cytoscint ES (MP Biomedicals, Solon, $\mathrm{OH}$, USA) and measured using scintillation spectrometry (BeckmanCoulter Instruments, LS 6500). Sodium-dependent uptake was determined by subtracting the signal in the choline-containing buffer from the signal in the sodium-containing buffer. The total concentration of substrate (radioactive and non-radioactive) was $0.5 \mu \mathrm{M}$ unless otherwise indicated. The $\mathrm{Na}^{+}$-independent signal observed was less than $5 \%$ of the total uptake in the presence of sodium.

\section{DATA ANALYSIS}

All values reported are the mean \pm SEM of at least three independent experiments that were performed on different days. Concentration-response curves were fit to one-site and two-site competition curves, and these fits were compared by $F$-test using Prism 5.0 (GraphPad Software Inc., La Jolla, CA, USA). The top of the curves were constrained to $100 \%$ (no inhibition), and for all three compounds, the maximal predicted inhibition from the curve fits was essentially $100 \%$ (complete inhibition). Kinetic analyses of glutamate transport performed in the absence and presence of HCP were fit by linear regression as Eadie-Hofstee plots. $K_{\mathrm{m}}$ and $V_{\max }$ values were compared using one-way ANOVA with a Bonferroni post hoc test using InStat (GraphPad Software Inc., La Jolla, CA, USA). The data for $\mathrm{L}-\left[{ }^{3} \mathrm{H}\right] \mathrm{Glu}, \mathrm{D}-\left[{ }^{3} \mathrm{H}\right] \mathrm{Asp}$, and $\left[{ }^{3} \mathrm{H}\right] \mathrm{GABA}$ uptake in cortex and cerebellum was analyzed using one-way ANOVA with a Bonferroni post hoc test using InStat.

\section{RESULTS}

We recently found that EGCG, a compound extracted from green tea that inhibits $\mathrm{GDH}(21)$, blocks $\mathrm{Na}^{+}$-dependent glutamate uptake in astrocytes. EGCG was only tested at a single concentration (1 mM) using a single concentration of glutamate (19). The goal of the present study was to determine if inhibition of GDH might inhibit $\mathrm{Na}^{+}$-dependent glutamate transport in membrane preparations from brain. As astrocytes in culture express GLAST and not GLT-1 $(22,23)$, we used crude membranes (P2) from cortex to further explore this effect. Genetic deletion of GLT-1 from mice essentially eliminates uptake from crude cortical membrane preparations (P2), and the pharmacology of glutamate uptake in this preparation parallels that observed for GLT-1 $(9,20,24)$. Although this is classically considered a subcellular fraction that contains nerve terminals, it also contains substantial amounts of astroglial elements $(25,26)$. We analyzed the subcellular distributions of two different glial glutamate transporters [GLT-1 and GLAST; $(15,16)$ ], a neuronal receptor [the NR1 subunit of the NMDA receptor; (1)], a glial cytoskeletal protein (GFAP), and a neuronal cytoskeletal protein [NF-L; (27); see Figure 1; Table 1]. The yield of both glutamate transporters was about $40 \%$ in the cortical P2 fraction and about $60 \%$ in the cerebellar P2 fraction, while the yield of NR1 was about 75\% in the cortical P2 fraction and only about $40 \%$ in the cerebellar P2 fraction. The yields of both cytoskeletal proteins were $10 \%$ or less in both the cerebellar and cortical P2 fractions. Together these studies show that the P2 fractions contain glial and neuronal membrane proteins consistent with the earlier studies $(25,26)$.

In the first set of experiments, the effects of increasing concentrations of EGCG on $\mathrm{Na}^{+}$-dependent uptake were examined (Figure 2A). The effects of EGCG were concentration-dependent and inhibited uptake with an $\mathrm{IC}_{50}$ value of $234 \mu \mathrm{M}$. The maximal inhibition observed was $83 \%$ at $1 \mathrm{mM}$; higher concentrations were not tested because of solubility concerns. EGCG inhibits purified GDH with an $\operatorname{IC}_{50}$ value of $\sim 0.5 \mu \mathrm{M}(21,28)$, but EGCG is relatively hydrophilic and has limited stability in solution (29).

Several other inhibitors of GDH were recently identified in a high-throughput screen (28). We chose two additional inhibitors of GDH to reduce the likelihood that effects of EGCG on glutamate uptake might be attributed to a non-specific interaction with a target other than GDH. All three of these compounds interact with different sites on GDH (30). The first compound examined, hexachlorophene (HCP), caused a concentration-dependent inhibition of $\mathrm{Na}^{+}$-dependent glutamate uptake (Figure 2B). When these data were fit to a single site, the $\mathrm{IC}_{50}$ value was $3.9 \mu \mathrm{M}$,

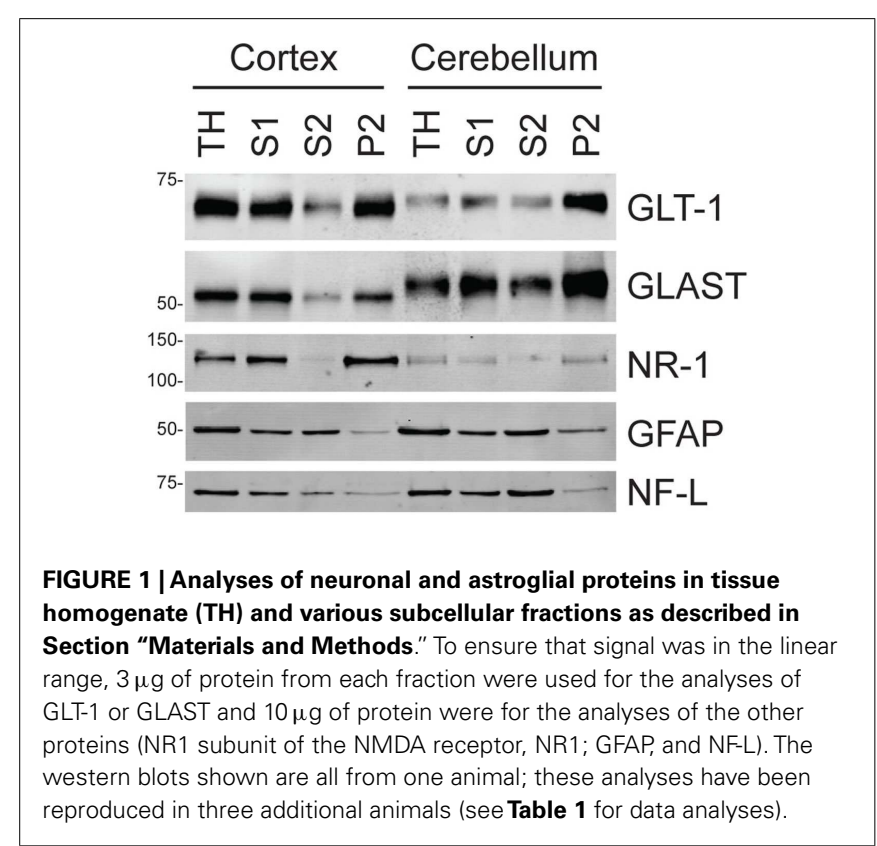


Table 1 | Analyses of neuronal and astroglial proteins in tissue homogenate (TH) and various subcellular fractionations as described in Section "Materials and Methods."

\begin{tabular}{|c|c|c|c|c|c|c|c|c|}
\hline & \multicolumn{2}{|c|}{ TH } & \multicolumn{2}{|c|}{ s1 } & \multicolumn{2}{|c|}{ S2 } & \multicolumn{2}{|c|}{$\mathbf{P 2}$} \\
\hline & Enrichment & Yield & Enrichment & Yield & Enrichment & Yield & Enrichment & Yield \\
\hline \multicolumn{9}{|l|}{ Cortex } \\
\hline GLT-1 & 1.0 & 100 & $1.1 \pm 0.2$ & $93 \pm 20$ & $0.44 \pm 0.06$ & $17 \pm 2$ & $1.2 \pm 0.4$ & $39 \pm 13$ \\
\hline GLAST & 1.0 & 100 & $1.4 \pm 0.3$ & $112 \pm 23$ & $0.41 \pm 0.07$ & $15 \pm 3$ & $1.2 \pm 0.4$ & $39 \pm 12$ \\
\hline NR1 & 1.0 & 100 & $1.3 \pm 0.2$ & $107 \pm 20$ & $0.14 \pm 0.005$ & $5.2 \pm 0.1$ & $2.3 \pm 0.4$ & $74 \pm 14$ \\
\hline NF-L & 1.0 & 100 & $0.42 \pm 0.09$ & $34 \pm 7$ & $0.23 \pm 0.04$ & $9 \pm 1$ & $0.3 \pm 0.1$ & $10 \pm 3$ \\
\hline \multicolumn{9}{|c|}{ Cerebellum } \\
\hline GLT-1 & 1.0 & 100 & $1.3 \pm 0.09$ & $100 \pm 5$ & $0.4 \pm 0.3$ & $13 \pm 8$ & $2.7 \pm 0.7$ & $67 \pm 20$ \\
\hline GLAST & 1.0 & 100 & $1.4 \pm 0.05$ & $108 \pm 2$ & $0.7 \pm 0.1$ & $22 \pm 4$ & $2.4 \pm 0.6$ & $59 \pm 17$ \\
\hline NR1 & 1.0 & 100 & $0.5 \pm 0.2$ & $36 \pm 14$ & $0.4 \pm 0.3$ & $14 \pm 10$ & $1.2 \pm 0.1$ & $37 \pm 9$ \\
\hline GFAP & 1.0 & 100 & $0.37 \pm 0.05$ & $28 \pm 4$ & $0.57 \pm 0.08$ & $19 \pm 2$ & $0.18 \pm 0.02$ & $4.4 \pm 0.7$ \\
\hline
\end{tabular}

Enrichment and yield are normalized to the levels of the tissue homogenate as described in Section "Materials and Methods." Data are the mean \pm SEM of at least three independent measurements.

but the inhibition data were best fit to two sites with $\mathrm{IC}_{50}$ values of $30 \mathrm{nM}$ and $14 \mu \mathrm{M}$. The maximal inhibition observed was $70 \%$ at $10 \mu \mathrm{M}$, and higher concentrations were not tested to avoid effects of solvent on uptake. The reported $\mathrm{IC}_{50}$ value for inhibition of $\mathrm{GDH}$ is $1.7 \mu \mathrm{M}$ (28). We also examined the effects of bithionol (BTH), which caused a concentration-dependent inhibition of $\mathrm{Na}^{+}$-dependent glutamate transport activity in crude cortical membranes (P2; Figure 2C). The $\mathrm{IC}_{50}$ value was $4.1 \mu \mathrm{M}$ when the data were fit to a single site, but the inhibition data were best fit to two sites with $\mathrm{IC}_{50}$ values of $84 \mathrm{nM}$ and $26 \mu \mathrm{M}$. The maximal inhibition observed was $60 \%$ at $10 \mu \mathrm{M}$, and higher concentrations were not tested to avoid effects of solvent on uptake. The reported $\mathrm{IC}_{50}$ value for inhibition of $\mathrm{GDH}$ is $5.5 \mu \mathrm{M}$ (28). Together, these studies show that three different inhibitors of GDH also inhibit $\mathrm{Na}^{+}$-dependent glutamate uptake in crude cortical membranes (P2).

One might expect that the effects of inhibition of GDH would increase with pre-incubation. To address this possibility, crude cortical membranes (P2) were pre-incubated with $6.0 \mu \mathrm{M} \mathrm{HCP}$ for up to $15 \mathrm{~min}$ prior to initiation of uptake by the addition of $\mathrm{L}^{-}\left[{ }^{3} \mathrm{H}\right] \mathrm{Glu}$. Somewhat surprisingly, the amount of inhibition observed with pre-incubations of $1,3,5,10$, and 15 min was not significantly different than that observed with no pre-incubation (Figure 3). In these experiments, the crude membranes (P2) were warmed to $37^{\circ} \mathrm{C}$ for the same amount of time, regardless of the length of the pre-incubation with HCP, to ensure the effects seen were independent of the increased time that the crude membranes (P2) were warmed to $37^{\circ} \mathrm{C}$. This shows that the effects of HCP on glutamate uptake are very rapid and essentially instantaneous in this experimental paradigm where uptake is measured for $3 \mathrm{~min}$.

To further characterize the mechanism of action, we examined the effects of HCP on the concentration-dependence for L- $\left[{ }^{3} \mathrm{H}\right]-$ Glu uptake. As was previously observed by us and others [for review, see (31)], the $K_{\mathrm{m}}$ for $\mathrm{L}-\left[{ }^{3} \mathrm{H}\right]$-Glu uptake was $\sim 5 \mu \mathrm{M}$ and the $V_{\max }$ was $\sim 1.2 \mathrm{nmol} / \mathrm{mg} / \mathrm{min}$. HCP had no effect on the $K_{\mathrm{m}}$ value and decreased the $V_{\max }$ for $\mathrm{L}_{-}\left[{ }^{3} \mathrm{H}\right]$-glutamate uptake (Figure 4). These data are consistent with a non-competitive mechanism of inhibition of glutamate uptake.

$\mathrm{Na}^{+}$-dependent glutamate uptake into crude cerebellar membranes (P2) displays a dramatically different pharmacology from that observed in crude cortical membranes [P2; $(20,32)]$. In fact, the pharmacology of transport in crude cerebellar membranes (P2) is consistent with that of GLAST (24). To determine if the effects of inhibition of GDH are selective for these two different transport activities, we compared the effects of HCP, EGCG, and BTH on $\mathrm{Na}^{+}$-dependent glutamate uptake in crude membranes (P2) prepared from cortex and cerebellum. None of the GDH inhibitors had any effect on $\mathrm{Na}^{+}$-dependent uptake in crude membranes (P2) prepared from cerebellum (Figure 5A).

D-Aspartate is transported by the $\mathrm{Na}^{+}$-dependent glutamate transporters (5), but is not a substrate for GDH (33). To determine if the effects of the GDH inhibitors might be related to direct metabolism of the glutamate that moves through the transporter during uptake, we examined the effects of the three different GDH inhibitors on $\mathrm{D}-\left[{ }^{3} \mathrm{H}\right]$-Asp uptake in crude membranes (P2) prepared from cortex and cerebellum. As was observed with $\mathrm{L}^{-}$ $\left[{ }^{3} \mathrm{H}\right]$-Glu transport, all three compounds inhibited $\mathrm{D}-\left[{ }^{3} \mathrm{H}\right]$-Asp uptake in crude cortical membranes (P2), and no effects were observed in cerebellar membranes (P2; Figure 5B).

The inhibitory neurotransmitter, $\gamma$-aminobutyric acid (GABA), is also cleared by $\mathrm{Na}^{+}$-dependent transport systems. The role of $\mathrm{GDH}$ in GABA metabolism is unclear, but it may play a role in the deamination of glutamate formed from the transamination of GABA by GABA-transaminase, also found in mitochondria [for discussions, see $(34,35)]$. Therefore, the effects of the three different GDH inhibitors on $\mathrm{Na}^{+}$-dependent $\left[{ }^{3} \mathrm{H}\right]$-GABA transport were examined in crude membranes $(\mathrm{P} 2)$ prepared from cortex and cerebellum. As was observed with $\mathrm{L}_{-}\left[{ }^{3} \mathrm{H}\right]$-Glu or D- $\left[{ }^{3} \mathrm{H}\right]-\mathrm{Asp}$, 

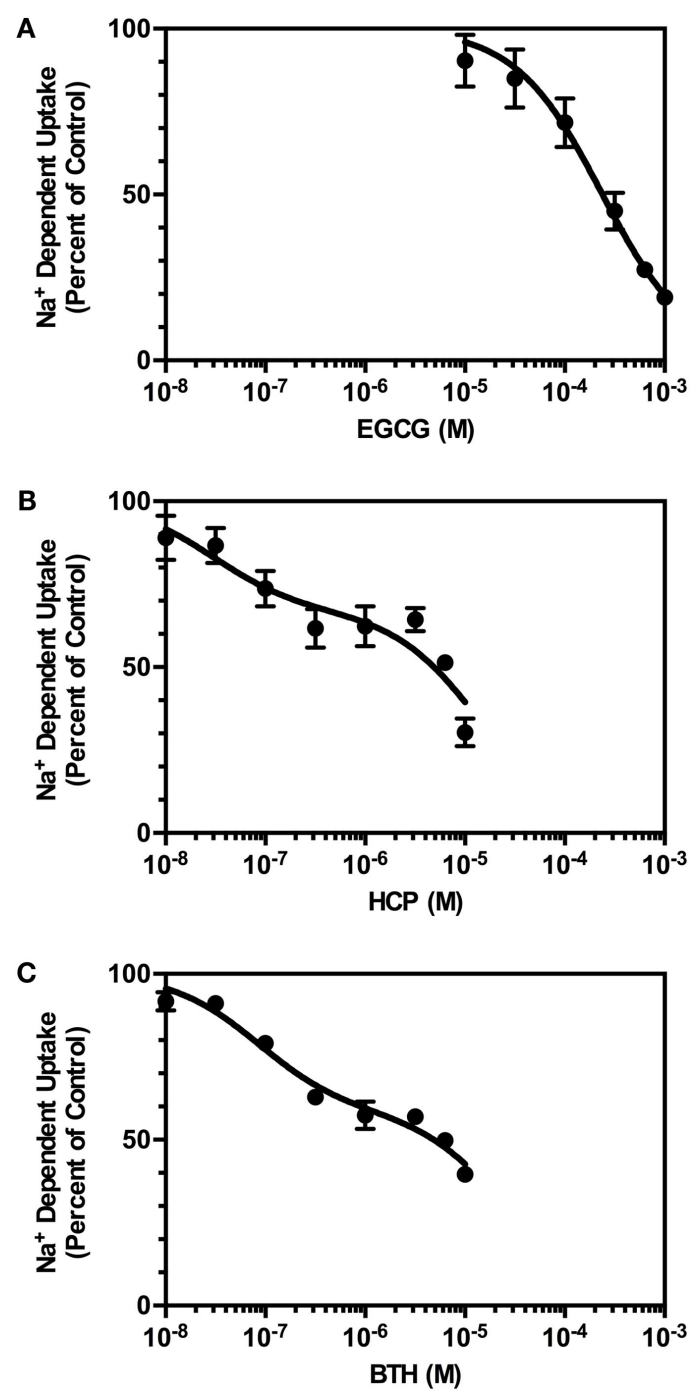

FIGURE 2 | Concentration-dependence of the effects of GDH inhibitors on of $\mathrm{Na}^{+}$-dependent $\mathrm{L}-\left[{ }^{3} \mathrm{H}\right]$-glutamate transport into crude membranes (P2) prepared from cortex. Transport of $L-\left[{ }^{3} \mathrm{H}\right]$-glutamate $(0.5 \mu \mathrm{M})$ was measured in the absence or presence of increasing concentrations of inhibitors, as described in Section "Materials and Methods." The percent of control represents the velocity of transport measured in the presence of inhibitor divided by that observed in the absence of inhibitor multiplied by 100. (A) Inhibition by EGCG was fit to a one-site competition model with an $I_{50}$ value of $234 \mu \mathrm{M}$. (B) Inhibition by HCP was fit to a two-site competition model. The $\mathrm{IC}_{50}$ value for the high affinity component was $30 \mathrm{nM}$, and the $I C_{50}$ value for the lower affinity component was $14 \mu \mathrm{M}$. Based on this fit, $33 \%$ of the sites were high affinity and $67 \%$ were of lower affinity. (C) Inhibition by BTH was fit to a two-site competition model with an $\mathrm{IC}_{50}$ for fraction $1(42 \%)$ of $84 \mathrm{nM}$ and an $\mathrm{IC}_{50}$ for fraction $2(58 \%)$ of $26 \mu \mathrm{M}$. Data are the mean \pm SEM of at least three independent measurements (except for incubation of $1 \mu \mathrm{M} \mathrm{BTH}$, of which there were only two observations)

all three GDH inhibitors reduced $\mathrm{Na}^{+}$-dependent $\left[{ }^{3} \mathrm{H}\right]$-GABA transport in cortical membranes ( $\mathrm{P} 2$; Figure $5 \mathrm{C})$. However, in contrast to the lack of inhibition observed with $\mathrm{L}-\left[{ }^{3} \mathrm{H}\right]-$ Glu or $\mathrm{D}-\left[{ }^{3} \mathrm{H}\right]-$ Asp, all three compounds also inhibited $\left[{ }^{3} \mathrm{H}\right]-\mathrm{GABA}$ transport in crude cerebellar membranes (P2).

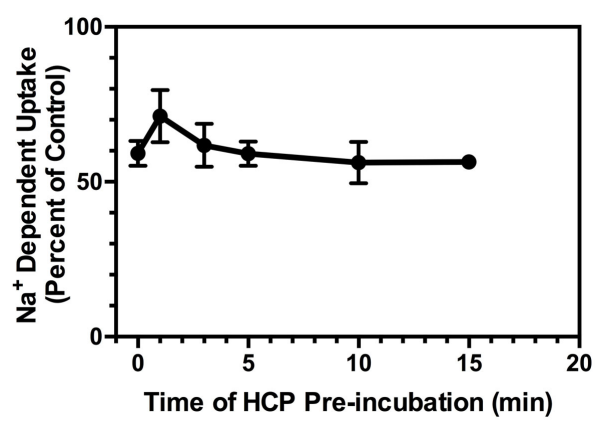

FIGURE 3 | Effects of pre-incubation with HCP (6 $\mu \mathrm{M})$ on $\mathrm{Na}^{+}$-dependent $\mathrm{L}-\left[{ }^{3} \mathrm{H}\right]$-glutamate transport into crude membranes (P2) prepared from cortex. HCP (or vehicle) was added to crude membranes (P2) at $37^{\circ} \mathrm{C}$ at $1,3,5,10$, or 15 min prior to the initiation of transport with the addition of L- $\left[{ }^{3} \mathrm{H}\right]$-glutamate, or simultaneously with $\mathrm{L}-\left[{ }^{3} \mathrm{H}\right]$-glutamate (time $=0 \mathrm{~min}$ ). Percent of control represents the velocity of transport in the presence of inhibitor divided by that observed in the absence of inhibitor multiplied by 100 . Data are the mean \pm SEM of at least three independent measurements.

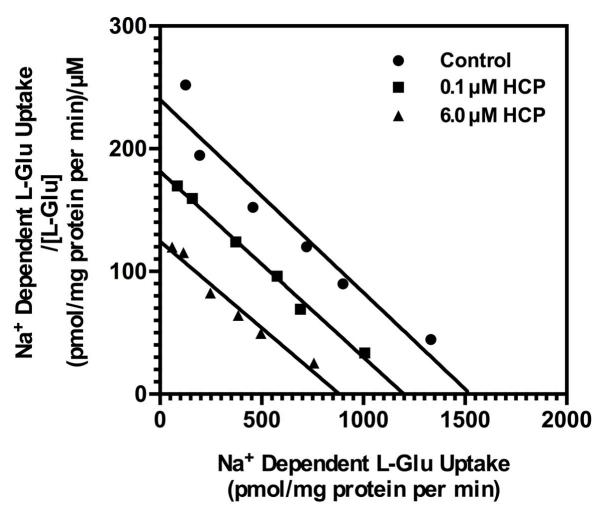

FIGURE 4 | Eadie-Hofstee plot of the concentration-dependence of $\mathrm{L}-\left[{ }^{3} \mathrm{H}\right]$-glutamate transport in crude membranes (P2) prepared from cortex with no treatment (control; circle), $0.1 \mu \mathrm{M}$ HCP (square), or 6.0 $\boldsymbol{\mu}$ M HCP (triangle). Uptake was determined as described in Section "Materials and Methods." Data presented are from a single experiment that has been repeated in four independent experiments with similar results. The $K_{\mathrm{m}}$ values for transport were $5.7 \pm 0.3 \mu \mathrm{M}$ in vehicle control, $5.4 \pm 0.4 \mu \mathrm{M}$ in the presence of $0.1 \mu \mathrm{M} \mathrm{HCP}$, and $4.2 \pm 1.0 \mu \mathrm{M}$ in the presence of $6.0 \mu \mathrm{M} \mathrm{HCP}$. The $V_{\max }$ values for transport were $1.6 \pm 0.4$ ( $\mathrm{nmol} / \mathrm{mg}$ protein/min) for vehicle control, $1.2 \pm 0.4$ in the presence of $0.1 \mu \mathrm{M} \mathrm{HCP}$, and $0.7 \pm 0.1$ in the presence of $6.0 \mu \mathrm{M} \mathrm{HCP}$. The $K_{\mathrm{m}}$ or $V_{\max }$ values were normalized to vehicle controls for each experiment (set to $100 \%$ ) and compared to those observed in the presence of HCP. HCP had no significant effect on $K_{\mathrm{m}}$ value, but significantly reduced the $V_{\max }$ value at either $0.1 \mu \mathrm{M}(p<0.01)$ or $6 \mu \mathrm{M}(p<0.001)$.

\section{DISCUSSION}

In a recent study, we obtained preliminary evidence that inhibition of GDH might lead to inhibition of $\mathrm{Na}^{+}$-dependent glutamate uptake (19). In the present study, we observed concentrationdependent inhibition of $\mathrm{Na}^{+}$-dependent glutamate uptake in crude membranes (P2) prepared from cortical tissue using three 

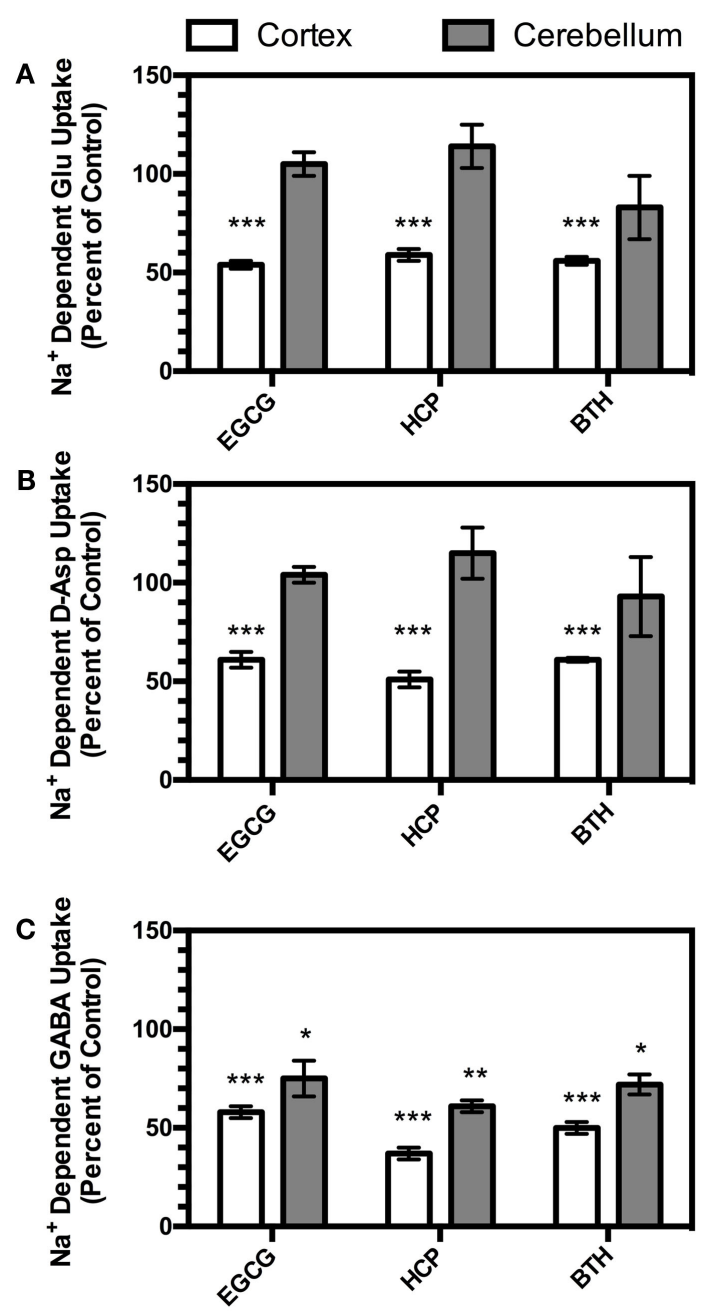

FIGURE 5 | Effects of EGCG $(300 \mu \mathrm{M})$, HCP $(6 \mu \mathrm{M})$, or BTH $(3 \mu \mathrm{M})$ on $\mathrm{Na}^{+}$-dependent transport of $\mathrm{L}$-glutamate (A), D-aspartate (B), or GABA (C) measured in crude membranes (P2) prepared from cortex (open bars) or cerebellum (shaded bars). Transport of all three substrates in both brain regions was measured in parallel experiments with different vehicle controls as described in the Section "Materials and Methods." Data are the mean \pm SEM from at least three independent experiments. Data were compared to vehicle controls by ANOVA. *Indicates a $p<0.05,{ }^{*}$ indicates a $p<0.01$, and ${ }^{* *}$ indicates a $p<0.001$.

different inhibitors of GDH. The effects of one of these inhibitors, HCP, were studied further. As pre-incubation did not increase the effects of HCP, inhibition occurs relatively rapidly (within seconds to minutes). HCP had no effect on $K_{\mathrm{m}}$ for glutamate uptake, but reduced $V_{\max }$, consistent with a non-competitive mechanism of action. All three compounds also inhibited $\mathrm{Na}^{+}$-dependent $\mathrm{D}^{-}$ $\left[{ }^{3} \mathrm{H}\right]$-Asp and $\left[{ }^{3} \mathrm{H}\right]$-GABA to a similar extent in crude cortical membranes (P2). However, in crude membranes (P2) prepared from cerebellum, these compounds did not affect $\mathrm{Na}^{+}$-dependent $\mathrm{L}-\left[{ }^{3} \mathrm{H}\right]-$ Glu or $\mathrm{D}-\left[{ }^{3} \mathrm{H}\right]-$ Asp, but did inhibit $\left[{ }^{3} \mathrm{H}\right]-\mathrm{GABA}$ transport.

The fact that three different inhibitors of GDH also block $\mathrm{Na}^{+}$dependent glutamate and GABA uptake suggests that the observed inhibition is likely to be due to an effect on GDH. The potencies of HCP or BTH for inhibition of glutamate uptake are similar to those observed for inhibition of GDH (all in the micromolar range - see Results). One concern is that the concentration of EGCG required to inhibit transport is approximately 500 -fold higher than that required to inhibit GDH; one major difference is that the analyses of GDH were conducted with purified enzyme (21). Others have shown that the EGCG is not particularly stable in solution, is subject to active efflux from some cellular systems by $\mathrm{ABC}$ cassette proteins, and may be poorly absorbed across membranes $(29,36)$. Therefore, it is possible that this difference in potency simply reflects the fact that glutamate uptake was measured in an intact system. Based on analyses of crystal structures of GDH, HCP and BTH bind to distinct locations in the interior of the GDH hexamer (30). Based on analyses with epicatechin 3monogallate (an EGCG analog), it seems that EGCG likely binds to the ADP-activation site, located by the pivot helix of GDH (37). We also considered the possibility that these compounds might block glutamate uptake through a direct interaction with GLT-1, but do not think this is likely for two different reasons. First, the fact that three different inhibitors have the same effect on uptake makes this a less likely explanation. Second, all three inhibitors block sodium-dependent GABA uptake as well, which is mediated by a completely distinct family of transporters that share no homology with the glutamate transporters [for review, see (38)]. Therefore, we suggest that the simplest explanation for the present results is that inhibition of GDH rapidly inhibits $\mathrm{Na}^{+}$-dependent glutamate or GABA uptake.

In the present study, we found that inhibition of GDH had no effect on L-glutamate or D-aspartate transport in crude cerebellar membranes (P2) where GLAST likely mediates uptake $(20,24,32)$. Yet, we previously found that EGCG inhibits glutamate uptake in astrocyte cultures (19) where uptake is also mediated by GLAST $(22,23,39)$. These measures of transport were conducted in identical buffers; this suggests that the differential effects cannot be attributed to the utilization of different exogenous metabolites to generate ATP. Coupling of GDH to transport may vary depending on the maturation of the system; astrocytes in culture are polygonal, not stellate shaped as is observed in vivo, and do not express GLT-1 consistent with an immature phenotype $(22,23)$. While maturation may explain the difference between astrocytes in culture and crude cerebellar membranes (P2), GDH has been recently deleted from the CNS tissues in mice (40) and also been knocked down in astrocytes in culture (41). Interestingly, the mice with the CNS specific deletion of GDH display no overt behavioral phenotype, and one would predict a seizure phenotype if deletion of GDH resulted in impaired glutamate uptake in vivo $(42,43)$. Therefore, as has been observed with differential metabolism of glutamate in different systems or with increased neuronal activity [for reviews, see $(44,45)]$, it seems likely that redundant systems may be differentially engaged to support glutamate uptake.

In the present study, we used crude membranes (P2). Previous studies have demonstrated that the pharmacology of glutamate uptake in cortical crude membranes parallels that observed for GLT-1 and is distinct from that observed in cerebellar crude membranes uptake $(20,24,32)$. Furthermore, genetic deletion of GLT-1 reduces glutamate uptake in cortical crude membranes to $5 \%$ of control (9). These studies provide compelling evidence that uptake 
measured in cortical crude membranes is mediated by GLT- 1 and that uptake measured in cerebellar crude membranes is mediated by GLAST. We examined the abundance of a neuronal membrane protein, the NR1 subunit of the NMDA receptor, and two glial membrane proteins, GLT-1 and GLAST in this membrane preparation. As was previously observed $(25,26)$, we found that this fraction contains high levels of neuronal and glial membrane proteins. We also found low levels of the cytoskeletal proteins, GFAP and NF-L. The absence of large amounts of either cytoskeletal protein suggests that the membranes do not uniformly reseal into vesicles and that the resealed vesicles contain only a small fraction of the original cytosol. This conclusion is also supported by the observation that cortical and cerebellar crude membranes contain comparable levels of GLT-1 (Figure 1), even though no GLT-1mediated uptake is detected in cerebellar crude membranes (see above).

GLT-1 expression, when analyzed using immunohistochemical approaches $(7,15,16)$, in situ hybridization of mRNA $[(46,47)$, and for reviews, see $(4,5)]$, or bacterial artificial chromosome GLT-1 promoter reporter mice (48), is essentially restricted to astrocytes. However, there is also evidence that GLT-1 is expressed in some neurons in the CNS $(8,47,49)$. The $\mathrm{P} 2$ membrane preparation has also been used to examine the relative contributions of the different GABA transporters to uptake. The pharmacology of GABA transport in crude membranes (P2) is consistent with GAT-1 $(50,51)$, which is thought to be localized predominantly in neurons, but is also found in astrocytes [for review, see (52)]. Although GLT-1 is heavily enriched in astrocytes and GAT-1 is enriched in neurons, it is not possible to determine if the effects of inhibition of GDH are related to inhibition of neuronal or glial pools of this enzyme. This will need to be a topic of further investigation.

Glutamate dehydrogenase is a mitochondrial enzyme that catalyzes the reversible deamination of glutamate to $\alpha$-ketoglutarate [for reviews, see $(53,54)]$. This reaction is accompanied by the production of NADH that can be used to generate ATP; the downstream metabolism of $\alpha$-ketoglutarate through the tricarboxylic acid cycle will also generate ATP. Cytoplasmic glutamate moves into mitochondria by one of two different families of transporters; neither of these processes transport D-aspartate $(55,56)$. Furthermore, GDH does not metabolize D-Asp (33). Therefore, although it is theoretically possible that GDH might support inward transport by rapidly metabolizing glutamate and thereby maintaining a concentration gradient, this is unlikely because inhibition of GDH also blocks transport of $\mathrm{D}^{-}\left[{ }^{3} \mathrm{H}\right]$-Asp. Others have found that synaptosomes enriched from P2 contain relatively high levels of endogenous glutamate (57); therefore, it seems certain that the crude membranes (P2) used in the present study contain endogenous glutamate. Combined with the fact that these inhibitors also block GABA transport, these observations suggest that mitochondrial GDH provides energy for transport using endogenous glutamate to drive the $\mathrm{Na}^{+}$-dependent transport systems.

Several studies have demonstrated that inhibition of mitochondrial function impairs glutamate uptake. For example, the mitochondrial poisons, sodium azide, dinitrophenol, and antimycin
A, inhibit glutamate uptake in cultured astrocytes (58). In addition, $\mathrm{MPP}^{+}$and rotenone, inhibitors of complex 1 of the electron transport chain, inhibit glutamate clearance in both astrocytes and crude cerebral synaptosomes $(59,60)$. Opening mitochondrial $\mathrm{K}_{\mathrm{ATP}}$ channels can functionally support glutamate uptake in the presence of $\mathrm{MPP}^{+}(61)$. There is also evidence that glutamate transport couples to ionic changes in mitochondria. In fact, uptake is accompanied by an increase in mitochondrial $\mathrm{Na}^{+}$(62). Uptake is also accompanied by acidification of mitochondria (63). This may be dependent upon the mitochondrial glutamate-aspartate exchanger, Aralar, which co-transports a $\mathrm{H}^{+}$with glutamate (55), or the mitochondrial glutamate carrier, which transports glutamate with $\mathrm{a} \mathrm{H}^{+}$or in exchange for a hydroxyl ion (56). The fact that inhibitors of GDH block glutamate uptake provides further support for a functional interaction between transporters and mitochondria.

Epigallocatechin-monogallate is considered the most active of the green tea polyphenols, the likely active ingredients in green tea; the effects of EGCG on biological/pathological processes have been examined in numerous in vitro and in vivo studies. EGCG is of particular interest in the treatment of Alzheimer's and Parkinson's diseases because it exhibits neuroprotective effects such as radical scavenging, iron chelating, activation of PKC, and anti-apoptotic action [for review, see (64)]. In vivo studies have demonstrated the neuroprotective properties of EGCG. For example, these polyphenols improve spatial learning in aged rodents (65), they suppress peripheral nerve degeneration associated with sciatic nerve crush (66), and EGCG protects against hippocampal neuronal damage after global ischemia (67). In vitro, EGCG is protective at low concentrations, but at concentrations similar to those used in the present study, EGCG causes cell death in a neuroblastoma cell line (68). EGCG increases the amount of glutamate observed in the effluent upon depolarization of synaptosomes (69). In pancreatic $\beta$-cells, EGCG inhibits the increase in insulin secretion and glutamine oxidation caused by the stimulation of GDH (21). In most of these examples, it is unclear if the observed effects are related to inhibition of GDH or to the anti-oxidant activity of EGCG. Inhibition of GDH and glutamate uptake might contribute to some of the observed in vivo effects, but this will need to be resolved in future studies.

In summary, we show evidence that inhibition of the mitochondrial enzyme, GDH, can result in inhibition of $\mathrm{Na}^{+}$-dependent $\mathrm{L}$-glutamate or $\mathrm{D}$-aspartate uptake in mammalian cortex. It seems likely that this dependence on GDH is affected by factors that are yet to be defined.

\section{ACKNOWLEDGMENTS}

This work was supported by NIH R01 NS 077774 and P30 HD 06979. We are also grateful to Drs. Thomas Smith, Charlie Stanley, and Marc Yudkoff for their helpful comments and advice throughout this study. We would like to thank Elizabeth Krizman for her help teaching Brendan S. Whitelaw the transport assays and her help with the analyses of the subcellular fractionation. We would like to thank Dr. Virginia Lee and Dr. Jeffery D. Rothstein for their generous provision of the anti-GFAP antibody and the anti-GLT-1 antibody, respectively. 


\section{REFERENCES}

1. Sheng M, Hoogenraad CC. The postsynaptic architecture of excitatory synapses: a more quantitative view. Annu Rev Biochem (2007) 76:823-47. doi:10.1146/annurev. biochem.76.060805.160029

2. Doble A. The role of excitotoxicity in neurodegenerative disease: implications for therapy. Pharmacol Ther (1999) 81:163-221. doi:10. 1016/S0163-7258(98)00042-4

3. Olney J. Excitotoxicity, apoptosis and neuropsychiatric disorders. Curr Opin Pharmacol (2003) 3:101-9. doi:10.1016/S1471489202000024

4. Sims KD, Robinson MB. Expression patterns and regulation of glutamate transporters in the developing and adult nervous system. Crit Rev Neurobiol (1999) 13:169-97.

5. Danbolt NC. Glutamate uptake. Prog Neurobiol (2001) 65:1-105. doi:10.1016/S0301-0082(00) 00067-8

6. Sheldon AL, Robinson MB. The role of glutamate transporters in neurodegenerative diseases and potential opportunities for intervention. Neurochem Int (2007) 51:333-55. doi:10.1016/j.neuint.2007.03.012

7. Rothstein JD, Martin L, Levey AI, Dykes-Hoberg M, Jin L, Wu D, et al. Localization of neuronal and glial glutamate transporters. Neuron (1994) 13:713-25. doi:10.1016/ 0896-6273(94)90038-8

8. Chen W, Mahadomrongkul V, Berger UV, Bassan M, Desilva T, Tanaka K, et al. The glutamate transporter GLTla is expressed in excitatory terminals of mature hippocampal neurons. J Neurosci (2004) 24:1136-48. doi:10.1523/ JNEUROSCI.1586-03.2004

9. Tanaka K, Watase K, Manabe $T$, Yamada K, Watanabe M, Takahashi $\mathrm{K}$, et al. Epilepsy and exacerbation of brain injury in mice lacking the glutamate transporter GLT-1. Science (1997) 276:1699-702. doi:10.1126/ science.276.5319.1699

10. Robinson MB. The family of sodium-dependent glutamate transporters: a focus on the GLT1/EAAT2 subtype. Neurochem Int (1999) 33:479-91. doi:10.1016/ S0197-0186(98)00055-2

11. Torres GE, Gainetdinov RR, Caron MG. Plasma membrane monoamine transporters: structure, regulation and function. Nat Rev Neurosci (2003) 4:13-25. doi:10.1038/nrn 1008

12. Gether U, Andersen PH, Larsson OM, Schousboe A. Neurotransmitter transporters: molecular function of important drug targets. Trends Pharmacol Sci (2006) 27:375-83. doi:10.1016/j.tips.2006.05.003

13. Zerangue N, Kavanaugh MP. Flux coupling in a neuronal glutamate transporter. Nature (1996) 383:634-7. doi:10.1038/383634a0

14. Attwell D, Gibb A. Neuroenergetics and the kinetic design of excitatory synapses. Nat Rev Neurosci (2005) 6:841-9. doi:10.1038/nrn1784

15. Chaudhry FA, Lehre KP, Campagne MVL, Ottersen OP, Danbolt NC, Storm-Mathisen J. Glutamate transporters in glial plasma membranes: highly differentiated localizations revealed by quantitative ultrastructural immunocytochemistry. Neuron (1995) 15:711-20. doi:10.1016/ 0896-6273(95)90158-2

16. Lehre KP, Levy LM, Ottersen OP, Storm-Mathisen J, Danbolt NC. Differential expression of two glial glutamate transporters in the rat brain: quantitative and immunocytochemical observations. I Neurosci (1995) 15:1835-53.

17. Genda EN, Jackson JG, Sheldon AL, Locke SF, Greco TM, O’Donnell JC, et al. Co-compartmentalization of the astroglial glutamate transporter, GLT-1, with glycolytic enzymes and mitochondria. J Neurosci (2011) 31:18275-88. doi:10.1523/ JNEUROSCI.3305-11.2011

18. Rose EM, Koo JC, Antflick JE, Ahmed SM, Angers S, Hampson DR. Glutamate transporter coupling to Na,K-ATPase. J Neurosci (2009) 29:8143-55. doi:10.1523/ JNEUROSCI.1081-09.2009

19. Bauer DE, Jackson JG, Genda EN, Montoya MM, Yudkoff M, Robinson MB. The glutamate transporter, GLAST, participates in a macromolecular complex that supports glutamate metabolism. Neurochem Int (2012) 61:566-74.

20. Robinson MB, Hunter-Ensor M, Sinor J. Pharmacologically distinct sodium-dependent L$\left[{ }^{3} \mathrm{H}\right]$ glutamate transport processes in rat brain. Brain Res (1991) 544:196-202. doi:10.1016/00068993(91)90054-Y

21. Li C, Allen A, Kwagh J, Doliba NM, Qin W, Najafi $H$, et al. Green tea polyphenols modulate insulin secretion by inhibiting glutamate dehydrogenase. J Biol Chem (2006) 281:10214-21. doi:10.1074/ jbc.M512792200

22. Swanson RA, Liu J, Miller JW, Rothstein JD, Farrell K, Stein BA, et al. Neuronal regulation of glutamate transporter subtype expression in astrocytes. J Neurosci (1997) 17:932-40.
23. Schlag BD, Vondrasek JR, Munir M, Kalandadze A, Zelenaia OA, Rothstein JD, et al. Regulation of the glial $\mathrm{Na}^{+}$-dependent glutamate transporters by cyclic AMP analogs and neurons. Mol Pharmacol (1998) 53:355-69.

24. Arriza JL, Fairman WA, Wadiche JI, Murdoch GH, Kavanaugh MP, Amara SG. Functional comparisons of three glutamate transporter subtypes cloned from human motor cortex. J Neurosci (1994) 14:5559-69.

25. Henn FA, Anderson DJ, Rustad DG Glial contamination of synaptosomal fractions. Brain Res (1976) 101:341-4. doi:10.1016/00068993(76)90274-2

26. Gylys KH, Fein JA, Cole GM. Quantitative characterization of crude synaptosomal fraction (P-2) components by flow cytometry. J Neurosci Res (2000) 61:186-92. doi:10.1002/1097-4547(20000715) 61:2<186::AID-JNR9>3.0.CO;2-X

27. Fuchs E, Weber K. Intermediate filaments: structure, dynamics, function, and disease. Annu Rev Biochem (1994) 63:345-82. doi:10. 1146/annurev.bi.63.070194.002021

28. Li M, Allen A, Smith TJ. High throughput screening reveals several new classes of glutamate dehydrogenase inhibitors. Biochemistry (2007) 46:15089-102. doi:10.1021/ bi7018783

29. Hong J, Lu H, Meng X, Ryu JH, Hara Y, Yang CS. Stability, cellular uptake, biotransformation, and efflux of tea polyphenol (-)-epigallocatechin-3gallate in HT-29 human colon adenocarcinoma cells. Cancer Res (2002) 62:7241-6.

30. Li M, Smith CJ, Walker MT, Smith TJ. Novel inhibitors complexed with glutamate dehydrogenase: allosteric regulation by control of protein dynamics. J Bio Chem (2009) 284:22988-3000. doi: 10.1074/jbc.M109.020222

31. Robinson MB, Dowd LA. Heterogeneity and functional properties of subtypes of sodium-dependent glutamate transporters in the mammalian central nervous system. Adv Pharmacol (1997) 37:69-115. doi: 10.1016/S1054-3589(08)60948-5

32. Ferkany J, Coyle JT. Heterogeneity of sodium-dependent excitatory amino acid uptake mechanisms in rat brain. J Neurosci Res (1986) 16:491-503. doi:10.1002/jnr. 490160305

33. Fosse VM, Kolstad J, Fonnum F. A bioluminescence method for the measurement of L-glutamate: applications to the study of changes in the release of L-glutamate from lateral geniculate nucleus and superior colliculus after visual cortex ablation in rats. J Neurochem (1986) 47:340-9. doi:10.1111/j.1471-4159. 1986.tb04507.x

34. Schousboe I, Bro B, Schousboe A. Intramitochondrial localization of the 4-aminobutyrate-2oxoglutarate transaminase from ox brain. Biochem J (1977) 162:303-7.

35. Kreft M, Bak LK, Waagepetersen HS, Schousboe A. Aspects of astrocyte energy metabolism, amino acid neurotransmitter homoeostasis and metabolic compartmentation. ASN Neuro (2012) 4:187-99. doi:10.1042/AN20120007

36. Zhong Y, Chiou YS, Pan $\mathrm{MH}$, Shahidi F. Anti-inflammatory activity of lipophilic epigallocatechin gallate (EGCG) derivatives in LPSstimulated murine macrophages. Food Chem (2012) 134:742-8. doi: 10.1016/j.foodchem.2012.02.172

37. Li C, Li M, Chen P, Narayan S, Matschinsky FM, Bennett MJ, et al. Green tea polyphenols control dysregulated glutamate dehydrogenase in transgenic mice by hijacking the ADP activation site. I Biol Chem (2011) 286:34164-74. doi:10.1074/ jbc.M111.268599

38. Nelson N. The family of $\mathrm{Na}^{+} / \mathrm{Cl}^{-}$ neurotransmitter transporters. J Neurochem (1998) 71:1785-803. doi:10.1046/j.1471-4159.1998. 71051785. $\mathrm{x}$

39. Garlin AB, Sinor AD, Sinor JD, Jee SH, Grinspan JB, Robinson MB. Pharmacology of sodium-dependent high-affinity $\mathrm{L}-\left[{ }^{3} \mathrm{H}\right]$ glutamate transport in glial cultures. J Neurochem (1995) 64:2572-80. doi:10.1046/j.14714159.1995.64062572.x

40. Frigerio F, Karaca M, De Roo M, Mlynarik V, Skytt DM, Carobbio $S$, et al. Deletion of glutamate dehydrogenase 1 (Glud1) in the central nervous system affects glutamate handling without altering synaptic transmission. $\mathrm{J} \mathrm{Neu}$ rochem (2012) 123:342-8. doi:10. 1111/j.1471-4159.2012.07933.x

41. Skytt DM, Klawonn AM, Stridh MH, Pajecka K, Patruss Y, QuintanaCabrera R, et al. siRNA knock down of glutamate dehydrogenase in astrocytes affects glutamate metabolism leading to extensive accumulation of the neuroactive amino acids glutamate and aspartate. $\mathrm{Neu}$ rochem Int (2012) 61:490-7. doi:10. 1016/j.neuint.2012.04.014

42. Demarque M, Villeneuve N, Manent JB, Becq H, Represa A, Ben-Ari $\mathrm{Y}$, et al. Glutamate transporters 
prevent the generation of seizures in the developing rat neocortex. $J$ Neurosci (2004) 24:3289-94. doi:10. 1523/JNEUROSCI.5338-03.2004

43. Shimamoto K, Sakai R, Takaoka K, Yumoto N, Nakajima T, Amara SG, et al. Characterization of novel Lthreo- $\beta$-benzyloxy aspartate derivatives, potent blockers of the glutamate transporters. Mol Pharmacol (2004) 65:1008-15. doi:10.1124/ mol.65.4.1008

44. Schousboe A, Westergaard N, Sonnewald U, Petersen SB, Huang $\mathrm{R}$, Peng L, et al. Glutamate and glutamine metabolism and compartmentation in astrocytes. Dev Neurosci (1993) 15:359-66. doi:10. 1159/000111356

45. McKenna MC. The glutamateglutamine cycle is not stoichiometric: fates of glutamate in brain. J Neurosci Res (2007) 85:3347-58. doi:10.1002/jnr.21444

46. Torp R, Danbolt NC, Babaie E, Bjoras $\mathrm{M}$, Seeberg E, Storm-Mathisen J, et al. Differential expression of two glial glutamate transporters in the rat brain: an in situ hybridization study. Eur J Neurosci (1994) 6:936-42. doi:10.1111/j.1460-9568. 1994.tb00587.x

47. Schmitt A, Asan E, Puschel B, Jons T, Kugler P. Expression of the glutamate transporter GLT1 in neural cells of the rat central nervous system: non-radioactive in situ hybridization and comparative immunocytochemistry. Neuroscience (1996) 71:989-1004. doi:10. 1016/0306-4522(95)00477-7

48. Regan MR, Huang YH, Kim YS, Dykes-Hoberg MI, Jin L, Watkins AM, et al. Variations in promoter activity reveal a differential expression and physiology of glutamate transporters by glia in the developing and mature CNS. J Neurosci (2007) 27:6607-19. doi:10.1523/ JNEUROSCI.0790-07.2007

49. Furness DN, Dehnes Y, Akhtar AQ, Rossi DJ, Hamann M, Grutle NJ, et al. A quantitative assessment of glutamate uptake into hippocampal synaptic terminals and astrocytes: new insights into a neuronal role for excitatory amino acid transporter 2 (EAAT2). Neuroscience
(2008) 157:80-94. doi:10.1016/j. neuroscience.2008.08.043

50. Sutch RJ, Davies CC, Bowery NG. GABA release and uptake measured in crude synaptosomes from genetic absence epilepsy rats from Strasbourg (GAERS). Neurochem Int (1999) 34:415-25. doi:10.1016/ S0197-0186(99)00046-7

51. Ghasemi A, Sadidi A, Mohammadi M, Khoshbaten A, Asgari A. Paraoxon inhibits GABA uptake in brain synaptosomes. Toxicol In vitro (2007) 21:1499-504. doi:10.1016/j. tiv.2007.06.009

52. Borden LA. GABA transporter heterogeneity: pharmacology and cellular localization. Neurochem Int (1996) 29:335-56. doi:10.1016/ 0197-0186(95)00158-1

53. Plaitakis A, Zaganas I. Regulation of human glutamate dehydrogenases: implications for glutamate, ammonia and energy metabolism in brain. J Neurosci Res (2001) 66:899-908. doi:10.1002/jnr.10054

54. Li M, Li C, Allen A, Stanley CA, Smith TJ. The structure and allosteric regulation of mammalian ]. Arch Biochem Biophys (2012) 519:69-80. doi:10.1016/j.abb.2011. 10.015

55. Palmieri L, Pardo B, Lasorsa FM, Del Arco A, Kobayashi K, Iijima M, et al. Citrin and aralarl are $\mathrm{Ca}(2+)$ stimulated aspartate/glutamate transporters in mitochondria. EMBO J (2001) 20:5060-9. doi:10.1093/emboj/20.18.5060

56. Fiermonte G, Palmieri L, Todisco S, Agrimi G, Palmieri F, Walker JE. Identification of the mitochondrial glutamate transporter. Bacterial expression, reconstitution, functional characterization, and tissue distribution of two human isoforms. J Biol Chem (2002) 277:19289-94. doi:10.1074/ jbc.M201572200

57. Erecinska M, Zaleska MM, Nissim I, Nelson D, Dagani F, Yudkoff M. Glucose and synaptosomal glutamate metabolism: studies with [15N]glutamate. J Neurochem (1988) 51:892-902. doi:10.1111/j. 1471-4159.1988.tb01826.x

58. Swanson RA, Farrell K, Simon RP. Acidosis causes failure of astrocyte glutamate uptake during hypoxia.
J Cereb Blood Flow Metab (1995) 15:417-24. doi:10.1038/jcbfm.1995. 52

59. Di Monte DA, Tokar I, Langston JW. Impaired glutamate clearance as a consequence of energy failure caused by $\mathrm{MPP}(+)$ in astrocytic cultures. Toxicol Appl Pharmacol (1999) 158:296-302. doi:10. 1006/taap.1999.8717

60. Yang YL, Meng $\mathrm{CH}$, Ding $\mathrm{JH}$ He HR, Ellsworth K, Wu J, et al. Iptakalim hydrochloride protects cells against neurotoxin-induced glutamate transporter dysfunction in in vitro and in vivo models. Brain Res (2005) 1049:80-8. doi:10.1016/ j.brainres.2005.04.073

61. Sun XL, Zeng XN, Zhou F, Dai CP, Ding JH, Hu G. KATP channel openers facilitate glutamate uptake by GluTs in rat primary cultured astrocytes. Neuropsychopharmacology (2008) 33:1336-42. doi: 10.1038/sj.npp.1301501

62. Bernardinelli Y, Azarias G, Chatton JY. In situ fluorescence imaging of glutamate-evoked mitochondrial $\mathrm{Na}+$ responses in astrocytes. Glia (2006) 54:460-70. doi:10.1002/ glia.20387

63. Azarias G, Perreten H, Lengacher S, Poburko D, Demaurex N, Magistretti PJ, et al. Glutamate transport decreases mitochondrial $\mathrm{pH}$ and modulates oxidative metabolism in astrocytes. $\mathrm{J} \mathrm{Neu}$ rosci (2011) 31:3550-9. doi:10. 1523/JNEUROSCI.4378-10.2011

64. Mandel S, Youdim MB. Catechin polyphenols: neurodegeneration and neuroprotection in neurodegenerative diseases. Free Radic Biol Med (2004) 37:304-17. doi:10. 1016/j.freeradbiomed.2004.04.012

65. Haque AM, Hashimoto M, Katakura M, Tanabe Y, Hara Y, Shido O. Long-term administration of green tea catechins improves spatial cognition learning ability in rats. J Nutr (2006) 136:1043-7.

66. Renno WM, Al-Maghrebi M, Alshammari A, George P. ()-Epigallocatechin-3-gallate (EGCG) attenuates peripheral nerve degeneration in rat sciatic nerve crush injury. Neurochem Int (2013) 62:221-31. doi:10.1016/j.neuint.2012.12.018
67. Lee S, Suh S, Kim S. Protective effects of the green tea polyphenol (-)-epigallocatechin gallate against hippocampal neuronal damage after transient global ischemia in gerbils. Neurosci Lett (2000) 287:191-4. doi:10.1016/S03043940(00)01159-9

68. Levites Y, Amit T, Youdim MB, Mandel S. Involvement of protein kinase $\mathrm{C}$ activation and cell survival/cell cycle genes in green tea polyphenol (-)-epigallocatechin 3-gallate neuroprotective action. J Biol Chem (2002) 277:30574-80. doi:10.1074/ jbc.M202832200

69. Chou CW, Huang WJ, Tien LT, Wang SJ. (-)-Epigallocatechin gallate, the most active polyphenolic catechin in green tea, presynaptically facilitates $\mathrm{Ca} 2+$-dependent glutamate release via activation of protein kinase $\mathrm{C}$ in rat cerebral cortex. Synapse (2007) 61:889-902. doi: 10.1002/syn.20444

Conflict of Interest Statement: The authors declare that the research was conducted in the absence of any commercial or financial relationships that could be construed as a potential conflict of interest.

Received: 22 May 2013; paper pending published: 05 July 2013; accepted: 30 August 2013; published online: 17 September 2013.

Citation: Whitelaw BS and Robinson $M B$ (2013) Inhibitors of glutamate dehydrogenase block sodium-dependent glutamate uptake in rat brain membranes. Front. Endocrinol. 4:123. doi: 10.3389/fendo.2013.00123

This article was submitted to Cellular Endocrinology, a section of the journal Frontiers in Endocrinology.

Copyright (C) 2013 Whitelaw and Robinson. This is an open-access article distributed under the terms of the Creative Commons Attribution License (CC BY). The use, distribution or reproduction in other forums is permitted, provided the original author(s) or licensor are credited and that the original publication in this journal is cited, in accordance with accepted academic practice. No use, distribution or reproduction is permitted which does not comply with these terms. 